ISSN 0258-7122

Bangladesh J. Agril. Res. 39(3): 385-396, September 2014

\title{
DIVERGENCE ANALYSIS OF DROUGHT TOLERANT GENOTYPES OF WHEAT (Triticum astivum L.)
}

\author{
M. A. ZAMAN ${ }^{1}$, M. N. A. SIDDQUIE ${ }^{2}$, M. MAHBUBUR RAHMAN ${ }^{3}$ \\ M. Y. ABIDA ${ }^{4}$ AND M. J. ISLAM ${ }^{5}$
}

\begin{abstract}
Thirty genotypes of wheat were grown in an Alpha Lattice Design with three replications for evaluation and divergence analysis. Seeds were sown on 24 November 2011 at Regional Wheat Research Centre, Bangladesh Agricultural Research Institute, Shyampur, Rajshahi. Significant variation was observed among the genotypes and these are grouped into six clusters. Clusters III and VI were comprised of maximum number of genotypes (6) followed by clusters I, $\mathrm{IV}$, and $\mathrm{V}$ with 5 genotypes and the minimum genotypes (3) were in cluster II. The maximum inter-cluster distance was recorded between the Cluster VI and Cluster II followed by cluster III and Cluster II, which indicates that genotypes belonging to these distant clusters could be used in hybridization programme for getting a wide spectrum of variation among the segregates. The minimum intercluster distance was found between the Cluster IV and Cluster I followed by that of Cluster V and Cluster IV. The maximum intra-cluster distance was recorded in Cluster II, consisted of three genotypes of diverse origin followed by Cluster $\mathrm{V}$ consisting of five genotypes which indicated that the genotypes of these clusters might have considerable diversity among themselves. While the minimum distance was computed in Cluster I composed of five genotypes which indicated that these genotypes were genetically very close to each other. Considering the eigenvalues of all principal component analysis the PC1, PC2, PC 3 , PC4, and PC5 with values contributed $30.78 \%, 20.11 \%, 17.75 \%, 10.93 \%$, and $7.63 \%$, respectively, of the total variation. The results revealed from the present study that the first principal component had high positive component loading from grains/spike and high negative loading from grain yield. Considering the clusters mean value, the genotype of Cluster II and VI are most divergent and maximum heterosis and wide variability in genetic architecture may be expected from the crosses between the genotypes belonged to these clusters. More specifically the cluster II could be selected for dwarf in nature, early heading and maturity and bold grain size. The genotypes from the cluster IV could be selected for maximum spikes $/ \mathrm{m}^{2}$ and maximum grain yield. The positive value of both vectors for days to heading and spikes $/ \mathrm{m}^{2}$ indicated that these traits had the highest contribution towards divergence among the 30 drought tolerant wheat genotypes.
\end{abstract}

Keywords: Heritability, divergence, $\mathrm{D}^{2}$ distance, genotype, hybridization and wheat.

${ }^{1,3,4 \& 5}$ Scientific Officer, RWRC, Bangladesh Agricultural Research Institute (BARI), Shyampur, Rajshahi, ${ }^{2}$ Senior Scientific Officer, RWRC, BARI, Shyampur, Rajshahi, Bangladesh. 


\section{Introduction}

Wheat is the second most important cereal crop of Bangladesh after rice. Major wheat growing area is North and Western parts of Bangladesh. About 0.995 million metric tons of wheat was produced from 0.358 million ha of land and where national average yield was 2.78 metric tons per hectare in 2012 (DAE, 2013). Drought in Bangladesh normally affects about 2.3 million ha of cropland from April to September and 1.2 million ha in the dry season, from October to March (Selvaraju Ramamasy, 2007). Besides, there are 1600 square kilometres Barind area in Rajshahi, Chapainawabganj, and Naogaon districts of Bangladesh are potential for wheat cultivation if drought tolerant genotypes are available.

Wheat Research Centre, Bangladesh Agricultural Research Institute has a strong collaboration with CIMMYT. CIMMYT also has already developed some drought tolerant genotypes and these genotypes in different environments throughout the world. This provides an opportunity to select exotic genotypes that are suitable for environmental condition. It is also essential to know the genetic diversity of these genotypes before taking any hybridization programme for incorporating drought tolerant gene in our existing popular varieties of wheat. Because genetic diversity is the pre-requisite for obtaining suitable segregants with desirable traits. Genetic diversity is also indispensible for the improvement of wider adaption to stress environments like drought, salinity, and heat tolerance, desirable quality and pest resistance (Nevo et al., 1982). Therefore, the objective of this study was to evaluate some CIMMYT drought tolerant advance lines and select the promising ones for high grain yields under drought/rainfed condition. Moreover, the highly divergent genotypes will be identified for using in the hybridization programme with our high yielding wheat varieties for getting the better gene combination, especially adapted to drought prone areas of Bangladesh.

\section{Materials and Method}

An experiment with 30 wheat genotypes received from CIMMYT (including a check variety Prodip) was sown in an Alpha-lattice design with three replications at RWRC, Rajshahi on 24 November 2011. Fertilizers were applied @ $\mathrm{N}_{100} \mathrm{P}_{26}$ $\mathrm{K}_{50} \mathrm{~S}_{20} \mathrm{~B}_{1} \mathrm{~kg} / \mathrm{ha}$ but one-third of total urea was top dressed after first irrigation. The experiment was conducted under rainfed condition but only one irrigation was given at three weeks after sowing for better crop establishment. The unit plot size was $5 \mathrm{~m}$ long with 6 rows spaced at $20 \mathrm{~cm}$. All recommended intercultural operations were done properly for getting better crop performance. Data were recorded on different agronomic characters, such as days to heading, days to maturity, plant height, number of spikes $/ \mathrm{m}^{2}$, spikes/plant, grains/spike, thousand grain weight and grain yield/ha. The middle four rows were harvested to get grain yield data for each plot and then converted into $\mathrm{kg}$ per hectare. All data 
were analysed using Alpha lattice computer based software programme and divergence was analysed using the Genstat Third edition software based programme.

\section{Results and Discussion}

\section{Evaluation of performance of the genotypes}

Significant variations were observed among the tested entries for days to heading, plant height, 1000-grain weight, grain yield, and other other agronomical traits (Table 1). Among 30 entries, only two showed lower yield than the check variety Prodip. All of the tested entries were late in days to heading and maturity compared to the check. Days to heading ranged from 66 to 82 days and days to maturity ranged 102-114 days. Thousand grain weight ranged from 53.35 to $34.81 \mathrm{~g}$. The maximum 1000-grain weight was recorded from the check variety Prodip and the minimum from the entry E-9 with minimum grain production. Grain yield ranged from 4812.18 to $3676.93 \mathrm{~kg} / \mathrm{ha}$. The maximum grain yield $(4812.18 \mathrm{~kg} / \mathrm{ha})$ was recorded from the entry E- 12 . Most of the tested entries were good in agronomic performance. The genotypes G-12, G -14, G -25, G -20, G-23, G-18, G-24, G-10, G-13, G-26, G-27, G-4, G5, G-15, and G-6 outyielded the check variety BARI Gom 24 (Prodip) significantly. Considering the other yield contributing characters (grains/spike and agronomic characters) the genotypes G-11, G-18, G-22, and G-23 were selected for further evaluation under more drought stress environment.

\section{Genetic divergence analysis}

The analysis of variance and dispersion showed highly significant variations among the different genotypes for all the nine characters under study, which revealed the presence of considerable diversity among the 30 genotypes. All the 30 genotypes were grouped into six clusters (Table 2). The maximum number of genotypes (6) was grouped into cluster III and cluster VI followed by 5 in cluster I, IV, and V. The minimum genotypes (3) was in cluster II. These results were constructed based on the principal component analysis. Daniel et al. (2010) carried out principal component analysis and cluster analysis with 49 bread wheat and grouped the genotypes into 22 different clusters. Bansal et al. (1990) reported that clustering pattern was influenced by the pedigree of breeding lines. According to Zaman et al. (2010) reported that the selection may produce genetically diverse genotypes with same pedigree. 
Table 1. Mean performance of yield and yield contributing traits of 30 drought tolerant genotypes of CIMMYT at RWRC, ${ }_{\infty}^{w}$ Rajshahi, 2011-12.

\begin{tabular}{|c|c|c|c|c|c|c|c|c|c|}
\hline $\begin{array}{c}\text { Genotype } \\
\text { no. }\end{array}$ & $\begin{array}{l}\text { Plant height } \\
(\mathrm{cm})\end{array}$ & $\begin{array}{c}\text { Heading } \\
\text { (days) }\end{array}$ & $\begin{array}{c}\text { Maturity } \\
\text { (days) }\end{array}$ & $\begin{array}{l}\text { Spikes/ } \\
\mathrm{m}^{2} \text { (no.) }\end{array}$ & $\begin{array}{l}\text { Spikelets/ } \\
\text { spike } \\
\text { (no.) }\end{array}$ & $\begin{array}{c}\text { Grains/ } \\
\text { spike(no.) }\end{array}$ & $\begin{array}{l}\text { TGW } \\
(\mathrm{g})\end{array}$ & $\begin{array}{l}\text { Grain yield } \\
\text { (kg/ha) }\end{array}$ & $\begin{array}{l}\text { Agronomic } \\
\text { score }\end{array}$ \\
\hline 2 & 112.58 & 78 & 111 & 364 & 20 & 62 & 37.45 & 4059.55 & 5 \\
\hline 3 & 110.62 & 75 & 109 & 332 & 19 & 55 & 40.74 & 4312.31 & 5 \\
\hline 4 & 106.32 & 73 & 112 & 329 & 18 & 53 & 40.10 & 4419.58 & 5 \\
\hline 6 & 102.55 & 76 & 111 & 385 & 18 & 50 & 42.27 & 4339.39 & 4 \\
\hline 7 & 94.22 & 80 & 114 & 364 & 19 & 49 & 37.29 & 4080.61 & 3 \\
\hline 8 & 106.9 & 82 & 113 & 318 & 18 & 56 & 40.19 & 4242.85 & 4 \\
\hline 9 & 101.81 & 80 & 112 & 375 & 18 & 52 & 34.81 & 3676.93 & 5 \\
\hline 13 & 97.29 & 78 & 114 & 324 & 19 & 53 & 41.01 & 4498.97 & 4 \\
\hline 14 & 110.89 & 79 & 113 & 410 & 21 & 59 & 38.51 & 4748.97 & 5 \\
\hline 15 & 100.27 & 78 & 114 & 345 & 19 & 52 & 39.59 & 4350.37 & 4 \\
\hline 16 & 93.13 & 81 & 114 & 322 & 20 & 61 & 37.78 & 4093.65 & 4 \\
\hline 17 & 98.70 & 79 & 114 & 326 & 19 & 51 & 39.75 & 4218.19 & 3 \\
\hline $18^{*}$ & 97.14 & 67 & 107 & 312 & 20 & 59 & 38.48 & 4613.14 & 4 \\
\hline
\end{tabular}


Table 1. Cont'd.

\begin{tabular}{|c|c|c|c|c|c|c|c|c|c|}
\hline $\begin{array}{c}\text { Genotype } \\
\text { no. }\end{array}$ & $\begin{array}{l}\text { Plant height } \\
(\mathrm{cm})\end{array}$ & $\begin{array}{c}\text { Heading } \\
\text { (days) }\end{array}$ & $\begin{array}{c}\text { Maturity } \\
\text { (days) }\end{array}$ & $\begin{array}{l}\text { Spikes/ } \\
\mathrm{m}^{2} \text { (no.) }\end{array}$ & $\begin{array}{l}\text { Spikelets/ } \\
\text { spike } \\
\text { (no.) }\end{array}$ & $\begin{array}{c}\text { Grains/ } \\
\text { spike(no.) }\end{array}$ & $\begin{array}{l}\text { TGW } \\
(\mathrm{g})\end{array}$ & $\begin{array}{c}\text { Grain yield } \\
\text { (kg/ha) }\end{array}$ & $\begin{array}{l}\text { Agronomic } \\
\text { score }\end{array}$ \\
\hline 20 & 99.32 & 81 & 114 & 365 & 17 & 50 & 43.48 & 4650.52 & 4 \\
\hline 21 & 108.95 & 75 & 108 & 371 & 19 & 53 & 35.82 & 4189.23 & 4 \\
\hline $22 *$ & 107.49 & 65 & 106 & 283 & 17 & 61 & 41.16 & 4130.04 & 4 \\
\hline 24 & 93.52 & 71 & 108 & 345 & 18 & 54 & 38.05 & 4526.60 & 4 \\
\hline 25 & 106.82 & 76 & 109 & 386 & 17 & 46 & 39.53 & 4726.14 & 4 \\
\hline 26 & 110.03 & 76 & 108 & 344 & 19 & 57 & 39.47 & 4479.00 & 5 \\
\hline 27 & 106.94 & 79 & 111 & 352 & 18 & 50 & 42.62 & 4472.27 & 5 \\
\hline Mean & 102.89 & 75.39 & 110.29 & 343 & 19 & 54 & 40.38 & 4324.72 & 4 \\
\hline LSD & 3.66 & 1.55 & 2.25 & 48.2 & 1.50 & 8.94 & 0.43 & 434.62 & 0.73 \\
\hline $\mathrm{CV}(\%)$ & 2.16 & 1.25 & 1.24 & 8.55 & 4.88 & 10.01 & 3.27 & 6.10 & 10.7 \\
\hline Sig. Level & $* *$ & $* *$ & $* *$ & $* *$ & $*$ & $* *$ & $* *$ & $* *$ & $* *$ \\
\hline
\end{tabular}


Table 2. Distribution of 30 wheat genotypes in six different clusters.

\begin{tabular}{l|c|c|c}
\hline No. of clusters & No. of genotypes & $\begin{array}{c}\text { Percentage of total } \\
\text { entries }\end{array}$ & \multicolumn{1}{c}{ Genotypes nos. } \\
\hline Cluster I & 05 & 16.67 & $3,5,6,15$, and 28 \\
Cluster II & 03 & 10.00 & 1,9, and 30 \\
Cluster III & 06 & 20.00 & $4,10,13,24,26$, and 27 \\
Cluster IV & 05 & 16.67 & $8,11,17,19$, and 21 \\
Cluster V & 05 & 16.67 & $2,7,16,22$, and 29 \\
Cluster VI & 06 & 20.00 & $12,14,18,20,23$, and 25 \\
\hline
\end{tabular}

\section{Estimation of genetic distance}

The average inter and intra clusters distance were estimated to compute the intracluster Mahalanobis's $\mathrm{D}^{2}$ values. The inter and intra cluster distance $\left(\mathrm{D}^{2}\right)$ values were presented in Table 3. The inter-cluster distances were larger than the intracluster distances which indicated the wider genetic diversity among the tested genotypes of different groups. Similar findings were reported by Samal and Jagadev (1996) and Ahmed et al. (2002). Divergences values are helpful for deciding the type of cluster for the purpose of further selection and the choice of parents for hybridization (Jagadev and Samal, 1991). Higher inter and intra cluster distances indicate higher genetic variability among the genotypes between and within clusters, respectively. The maximum inter-cluster distance (27.254) was recorded between the Cluster VI and Cluster II followed by Cluster III and Cluster II, indicating that genotypes belonging to these distant clusters could be used in hybridization programme for getting a wide spectrum of variation among the segregates. Similar finding was recorded by Mahabubur Rahman (2012) and Chowdhury et al. (2006). The minimum inter-cluster distance (4.038) was found between the Cluster IV and Cluster I followed by Cluster V and Cluster IV. These relationships were also reflected in the scatter diagram (Fig. 1). On the other hand, the intra-cluster distances were computed by the values of intergenotypic distance matrix of PCO. There was remarkable variation in intracluster divergence, which varied from 0.50620 to 0.20064 (Table 3). The maximum intra-cluster distance (0.50620) was recorded in Cluster II consisting of three genotypes of diverse origin followed by Cluster V (0.34683), consisted of five genotypes, indicating that the genotypes of these clusters might have considerable diversity among them. While the minimum distance was observed in Cluster I composed of five genotypes which indicated that these genotypes were genetically very close to each other. 
Table 3. Average intra (bold) and inter-cluster distance.

\begin{tabular}{l|l|l|l|l|l|l}
\hline Cluster & Cluster I & Cluster II & Cluster III & Cluster IV & Cluster V & Cluster VI \\
\hline Cluster I & $\mathbf{0 . 2 0 0 6 4}$ & & & & & \\
Cluster II & 17.322 & $\mathbf{0 . 5 0 6 2 0}$ & & & & \\
Cluster III & 5.083 & 22.261 & $\mathbf{0 . 2 1 4 8 8}$ & & & \\
Cluster IV & 4.038 & 13.571 & 9.117 & $\mathbf{0 . 2 8 3 3 7}$ & & \\
Cluster V & 8.236 & 9.800 & 13.317 & 4.200 & $\mathbf{0 . 3 4 6 8 3}$ & \\
Cluster VI & 9.985 & 27.254 & 5.006 & 13.962 & 18.147 & $\mathbf{0 . 2 9 3 5 8}$ \\
\hline
\end{tabular}

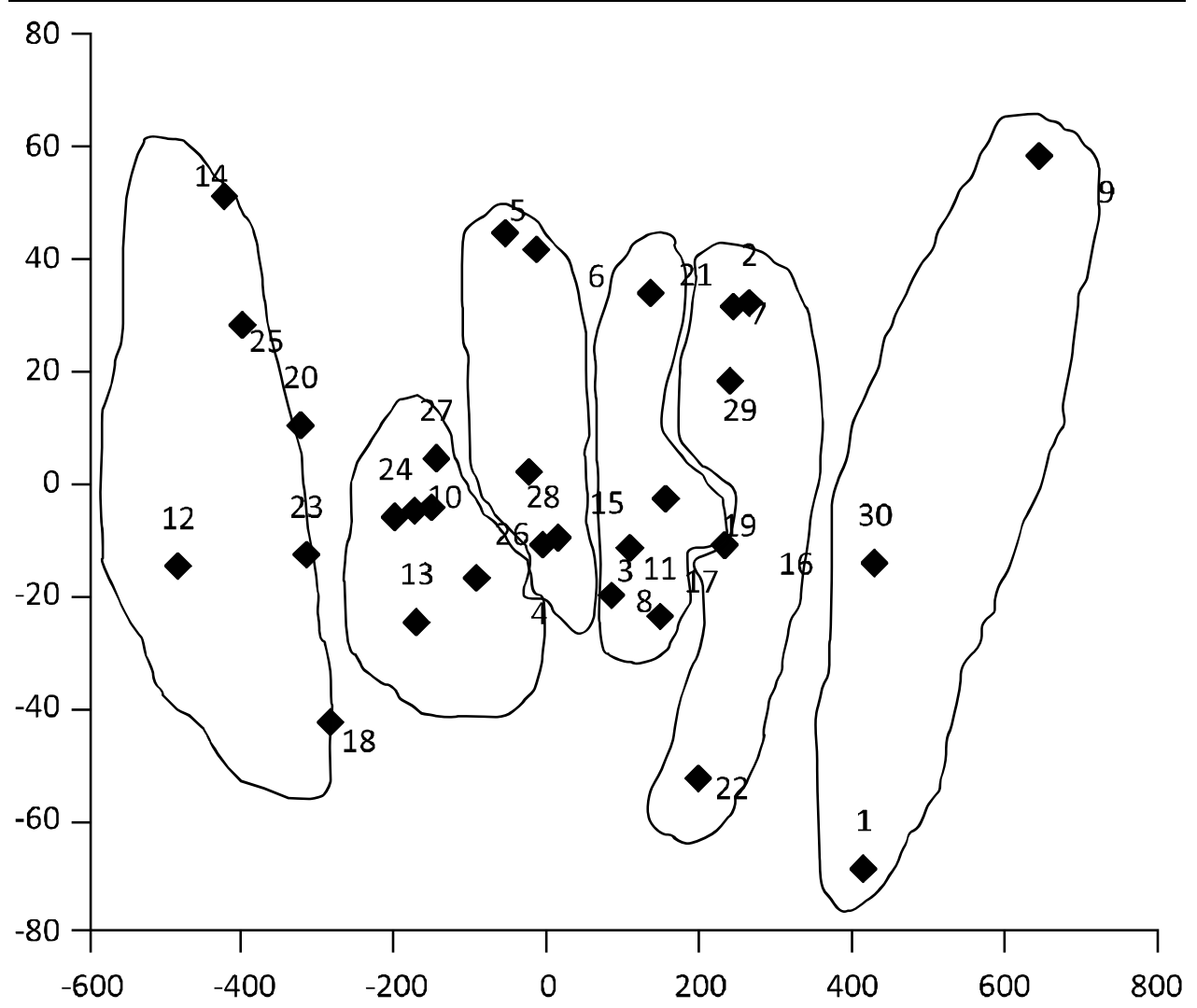

Figure 1. Distribution of 30 wheat genotypes in two dimensional scatter diagram based on their principal component scores superimposed with six clusters.

\section{Principal components analysis}

Principal component analysis (PCA) is important for the reflection of the highest contributor to the total variation at each axis of differentiation (Sharma et al., 1998). The eigen values from PCA are used for determination of how many factors to retain. The sum of the eigenvalues is equal to the number of variables. 
Table 4. Vector loadings and percentage explained variation by the first ten PCs.

\begin{tabular}{l|c|c|c|c|c|c|c|c|c}
\hline \multirow{2}{*}{\multicolumn{1}{c}{ Characters }} & \multicolumn{10}{c}{ Eigenvectors } \\
\cline { 2 - 11 } & PC1 & PC2 & PC3 & PC4 & PC5 & PC6 & PC7 & PC8 & PC9 \\
\hline Plant height (cm) & -0.00251 & 0.04129 & -0.80752 & 0.38605 & 0.41538 & 0.13106 & 0.03561 & -0.05790 & 0.05317 \\
Days to heading & 0.00012 & 0.09454 & 0.38481 & 0.66756 & 0.24411 & -0.21588 & -0.53551 & 0.06075 & -0.02627 \\
Days to maturity (days) & -0.00066 & 0.05519 & 0.32917 & 0.43909 & 0.12814 & 0.07137 & 0.82055 & -0.01154 & 0.02927 \\
Spikes/m ${ }^{2}$ & -0.03896 & 0.98956 & -0.03798 & -0.10182 & -0.06005 & -0.05830 & 0.01756 & 0.01052 & 0.00474 \\
Spikelets/spike & 0.00003 & -0.00113 & -0.00164 & 0.05506 & -0.10491 & -0.19382 & -0.00295 & -0.95910 & -0.16886 \\
Grains/spike & 0.00248 & -0.05063 & -0.29201 & 0.34822 & -0.72819 & -0.46465 & 0.08910 & 0.18469 & 0.05186 \\
1000-grain wt & 0.00010 & -0.05470 & -0.03575 & -0.27754 & 0.45444 & -0.82034 & 0.16889 & 0.10238 & -0.01495 \\
Agronomic score & -0.00040 & 0.00447 & -0.05899 & 0.02879 & -0.00785 & 0.03599 & 0.04344 & 0.16807 & -0.98193 \\
Yield (kg/ha) & -0.99923 & -0.03885 & 0.00263 & 0.00362 & -0.00052 & 0.00061 & -0.00115 & 0.00013 & 0.00017 \\
\hline Eigen value & 2.770 & 1.810 & 1.598 & 0.984 & 0.687 & 0.503 & 0.376 & 0.167 & 0.105 \\
Individual percentage & 30.78 & 20.11 & 17.75 & 10.93 & 7.63 & 5.59 & 4.18 & 1.86 & 1.17 \\
Cumulative percentage & 30.78 & 50.89 & 68.64 & 79.57 & 87.20 & 92.79 & 96.97 & 98.83 & 100.00 \\
\hline
\end{tabular}


From the present study, the first variables retain the information contained in 2.770 of the original variables (Table 4.). All principal components from PC1 to PC9 has been used based on original data and having latent roots greater than one, accounting nearly $100 \%$ of the total variation. Out of the total principal components retained, PC1, PC2, PC3, PC4, and PC5 with values of 30.78\%, $20.11 \%, 17.75 \%, 10.93 \%$, and $7.63 \%$, respectively was contributed to the total variation. Daniel Hailegiorgis et al., 2011. reported nearly $80 \%$ of the total variation using nine principal components extracted from the original data in case of bread wheat genotypes grown in Ethiopia.

According to Chahal and Gosal (2002), characters with latest absolute value closer to unity within the first principal component influence the clustering more than those with lower absolute value closer to zero. The results revealed from the present study that the first principal component had positive component loading from grains/spike and highest negative loading from grain yield. The positive and negative loading shows the presence of positive and negative correlation trends between the components and variables (Daniel Hailegiorgis et al., 2011). Similar trends were observed in the present study.

From the present study, the major contributing characters for the diversity in the second principal component $(\mathrm{PC} 2)$ were spikes $/ \mathrm{m}^{2}$; in principal component three (PC3) days to heading and days to maturity, 1000-grain weight and plant height in principal component PC5; days to maturity in principal component PC7. Hence, for the first group grains/spike is the best choice, which had the largest loading from component ones, spikes $/ \mathrm{m}^{2}$ for the second, days to heading for third, days to heading for fourth, thousand grain weight for fifth and days to maturity for seventh group.

\section{Cluster mean analysis}

The inter cluster means for nine characters were presented in Table 5. The results revealed that the clusters remarkably distinguished for most of the traits which indicated proper clustering. The genotypes of Cluster II were dwarf type $(99.50 \mathrm{~cm})$, with early heading (71 days), early maturity (105 days), good agronomic score (4.00), and large grain size $(43.60 \mathrm{~g})$ but their grain yield/ha minimum (3829 kg/ha). The maximum grain yield $(4699 \mathrm{~kg} / \mathrm{ha})$ was recorded from Cluster VI with maximum spikes $/ \mathrm{m}^{2}(361)$, higher plant height $(103.50 \mathrm{~cm})$, long duration, and medium grain size. 
Table 5. Mean performance of yield and yield attributes of eight clusters.

\begin{tabular}{lc|c|c|c|c|c}
\hline \multicolumn{1}{c}{ Characters } & Cluster I & Cluster II & $\begin{array}{c}\text { Cluster } \\
\text { III }\end{array}$ & $\begin{array}{c}\text { Cluster } \\
\text { IV }\end{array}$ & Cluster V & $\begin{array}{c}\text { Cluster } \\
\text { VI }\end{array}$ \\
\hline Plant height (cm) & 102.70 & 99.50 & 102.90 & 104.90 & 102.60 & 103.50 \\
Days to heading & 78 & 71 & 74 & 77 & 76 & 74 \\
Days to maturity & 112 & 105 & 110 & 111 & 112 & 110 \\
(days) & & & & & & \\
Spikes/m & 356 & 316 & 340 & 332 & 337 & 361 \\
Spikelets/spike & 19 & 19 & 18 & 18 & 19 & 19 \\
Grains/spike & 52 & 55 & 53 & 54 & 57 & 55 \\
1000-grain wt (g) & 40.70 & 43.6 & 41.0 & 39.2 & 38.9 & 40.0 \\
Yield (kg/ha) & 4343 & 3829 & 4483 & 4200 & 4090 & 4699 \\
Agronomic score & 4.20 & 4.00 & 4.70 & 4.20 & 4.00 & 4.30 \\
\hline
\end{tabular}

The cluster III ranked first for the maximum agronomic score (4.70) but in second position for grain yield (4483 kg/ha) and 1000-grain weight (41.00g).

Therefore, the genotypes belonging to Cluster II and VI are most divergent. So, maximum heterosis and wide variability in genetic architecture is expected from the crosses between the genotypes belonging to these clusters.

\section{Contribution of traits towards divergence}

The traits contributing maximum to the divergence are used to give greater emphasis for deciding on the cluster for the purpose of futher selection and in the choice of parents for hybridization (Jagadev and Samal, 1991). Contribution of traits towards divergence was obtained from Canonical Variate Analysis (CVA) are presented in Table 6. CVA revealed that both the vectors had positive values for days to heading, spikes $/ \mathrm{m}^{2}$, and 1000-grain weight which indicated that these traits had the highest contribution towards divergence among the 30 drought tolerant wheat genotypes. Therefore, the divergence in the present materials due to these traits is very much important for improvement of drought tolerance through selection of appropriate parents. Mahabubur Rahman (2011) studied 17 traits in 30 spring wheat genotypes traits and found that early ground coverage, initial plants $/ \mathrm{m}^{2}$, days to heading, peduncle length, and chlorophyll content of flag leaf at 21 days after anthesis and had the highest contribution towards total divergence which supports the findings of the present study. 
Table 6. Contribution of traits towards divergence based on latent vectors for ten traits of 30 genotypes.

\begin{tabular}{lcc}
\hline Traits & Latent Vector I & Latent Vector II \\
\hline Plant height $(\mathrm{cm})$ & 0.026 & -0.165 \\
Days to heading & 0.116 & 0.189 \\
Days to maturity (days) & -0.271 & -0.483 \\
Spikes $/ \mathrm{m}^{2}$ & 0.028 & 0.003 \\
Spikelets/spike & -0.252 & 0.224 \\
Grains/spike & 0.260 & -0.149 \\
1000-grain wt & 0.286 & 0.151 \\
Yield (kg/ha) & -0.019 & 0.000 \\
Agronomic score & -1.925 & 1.528 \\
\hline
\end{tabular}

\section{Selection of genotypes for future hybridization purpose}

Generally crosses involving parents belonging to most divergent clusters are expected to produce maximum heterosis and create wide variability in genetic architecture. Accessions among the cluster separated by high $\mathrm{D}^{2}$ values could be used in hybridization programme for obtaining wide spectrum of variations among the segregates (Seetharaman et al., 1988). The inter cluster distance between II and VI was the highest (27.254) followed by cluster II and III (22.261) and between the other clusters V and VI (18.147), Cluster I and II (17.322), Cluster II and IV(13.571) and Cluster III and V (13.317) were intermediate. Therefore, for getting more heterotic $\mathrm{F}_{1} \mathrm{~s}$, six pairs of clusters which are Cluster II \& VI, II \& III, V \& VI, I\& II, II \& IV and III \& V could be considered for this purpose.

Considering the magnitude of genetic distance, contribution of different traits towards the total divergence, magnitude of cluster means for different traits and field performance, the genotypes from the cluster II could be selected for dwarf type in nature, early days to heading, early days to maturity and bold grain size. The genotypes from the cluster VI could be selected for maximum spikes $/ \mathrm{m}^{2}$ and maximum grain yield. The genotypes from the cluster III could be selected for good agronomic characters.

Finally, on the basis of cluster distance and cluster mean genotypes of cluster II and VI should be considered as parent materials for future hybridization programme for getting maximum drought-tolerant high yielding genotypes. 


\section{References}

Ahmed, A. U., M. A. Sarker, J. A. Choudhury, N. Ara and M. M. Ali. 2002. Genetic divergence analysis in chickpea. Bangladesh J. Agril. Res. 27(1): 47-50.

Bansal, M. P., D. V. S. Panwar and M. R. Naidu. 1990. Genetic divergence among the breeding lines of diverse crosses of rice. Research and Development Reporter 7:90-96.

Chahal, G. S. and Gosal, S. S. 2002. Principles and procedures of Plant Breeding: Biotechnology and conventional approaches. Narosa Publishing House, New Delhi.

Chowdhury, M. J. A, A. K. M. M. Alam, H. Begum and M. J. Hasan. 2006. Genetic diversity of wheat (Triticum aestivum L.) genotypes for some quantitative trait: Dept. of Biotech, Bangladesh Agricultural University, Mymmensingh, piea811@yahoo.co,

Daniel Hailegiorgis, Mebrahton Mesfin and Tsige Genet. 2010. Genetic divergence analysis on some bread wheat genotypes grown in Ethiopia. J. of Central European Agriculture 12(2), p.344-352.

Department of Agricultural Extension (DAE). 2013. Agricultural Diary. Agriculture Information Service. Ministry of Agriculture, Khamarbari, Farmgate, Dhaka-1215.

Jagadeb, P. N. and K. M. Samal. 1991. Multivariate analysis in niger (Guizotica abyssinicacass). Indian J. Genet. 30(1): 212-221.

Nevo, E. E., A. Golenberg, A. H. D. Beilies, Brown and D. Zohary. 1982. Genetic diversity and environmental associations of wild wheat, in Israel. Theory and Applied Genetics 62:241-254.

Samal, K. M. and N. Jagadeb. 1996. Genetic divergence among chickpea cultivars. Indian J. Genet. 56(1):86-88.

Sharma, J. R., P. K. Gupta and Balyan. 1998. Genetic divergence is a large collection of wheat (Triticum spp.). Indian J. Genet. Pl. Breed. 58(3):271-278.

Selvaraju Ramamasy. 2007. Climate variability and change: adaptation to drought in Bangladesh. A Resource book and training guide, Asian Disaster Preparedness Center, Food and Agriculture Organization of the United Nations. Rome.

Seetharaman R., De N. R. M. K. Sinha and S. P. Banergee. 1988. Genetic divergence in rice. Indian J. Genet. 48: 189-194.

Zaman M. A, M. Tuhina-Khatun, M. Z. Ullah, M. Moniruzzamn and M. Z. Rahman. 2010. Multivariate analysis in advanced lines of mustard (Brassica spp.) Bangladesh J. Pl. Breed. Genet. 23(2): 29-34. 